of the lens of the other eye; but at present the right eye is clear, and in every respect appears perfect, with the exception of the tremulous condition of the iris as before noted ; yet the patient has very imperfect vision in this organ; for although it is more useful to him than his left eye, he has still not sufficient light to distinguish letters even of the largest print. The lens of the right eye, as he says, disappeared from the anterior chamber a few days before he entered, and it has not since fallen forward; according to his own report, he can plainly discover it, apparently like a bright round spot in one corner of the eye. Both irides are nearly immoveable by this impression of light, yet the pupils do contract just sufficiently to be observed when the eyes are suddenly opened. There appeared to be no reason for doubting the patient's statement in relation to his right eye. Thousands, he says, have examined it, and many physicians of New England have taken minutes of his case. They have probably not noticed the like affection of the right eye, owing to the dimness of the cornea. His first notice of this peculiar affection was a severe and sudden pain in the eye while he was stooping forward. On requesting some one near him to look into the eye, he was informed that a little bag of water hung inmediately before the sight. He lay down, covered his face with two or three folds of a handkerchief, and all at once the pain subsided, and the little bag of water disappeared. Subsequent to this, whenever he stooped, especially if in a dark place, or during a dark day, the lens would fall forward. In clear weather this was not the case, and on cloudy days, if the lens was not down, he could at will displace it, and this he was often induced to do, to satisfy the curiosity of his friends, or of strangers. But while the sun shone, or in a strong light, he could not do this. While the lens is down, there is always pain in the eye. We have tried the effect of convex glasses, and his sight is much better when he wears them. He is a stout, healthy man, and bas never suffered from any constitutional disease. He had visited the Eye Infirmary prior to admission, but neither there nor at the Hospital was it considered proper to attempt any operation for his relief. Note.-For another case of the preceding affection, see Medico-Chirur. April, 1833, page 299, from Damour's.

United States Medical and Surgical Journal.

\title{
A CASE OF ENCYSTED TUMOR SI'TUATED IN THE BICEPS-CRURIS
} MUSCLE.

BY J. P. METTAUER, M.D. PRINCE EDWARD COUNTY, VIRGINiA.

[Communicated for the Boston Medical and Surgical Journal.]

The case which forms the subject of this communication, had existed about fifteen years. The patient, at the time the operation was performed, was about fifty years of age, of sound constitution and good general health. The history furnished (by the patient himself) was, that about fifteen years ago, while sustaining a heavy weight, he felt something give way in the thigh, a little above the ham, causing him to sink under his burthen; attended with severe pain at the time, and succeeded by lame- 
ness of some days duration, with evident and well-defined soreness about the spot. The soreness as well as the lameness subsiding after a week or two, no further notice was taken of the injury for several months. At this time a small tumor was discovered, and seemed to occupy exactly the situation in which the sensations of giving way and pain had been felt. When first perceived, the tumor was about the size of a nutmeg, hard, and regularly formed. From this period it enlarged progressively, but slowly, impairing the motions of the limb, and beconing more and more painful as it increased in size. About a year before the tumor was removed, its growth was rapid, and it was very painful at times.

When I examined the case, an enlargement presented, fully eleven inches in length, and four or five in thickness, of unequal surface and very firm and elastic. The tumor occupied fully three-fifths of the biceps-flexor-cruris ; extending, by a bagging elongation, below the ham. Long pressure in the ham had interrupted the circulation so as to dilate the veins below it, which in many parts of the leg, were in a varicose state. The motions of flexion and extension, though they varied its firmness and prominence, did not materially change the position of the tumor ; it was less fixed and hard when the limb was flexed, and could also be made to glide from side to side when in this position.

The nıagnitude of the tumor, its progressive and rapid growth, together with the increasing pain and helplessness of the limb, determined ine to attempt its removal, which was executed as follows. The patient was extended on a long table, with his back uppermost. A longitudinal incision was now made, commencing two inches above the femoral extremity of the tumor, and continued three inches below the ham. A transverse section was next made on one side, a little exterior to the outer margin of the biceps. These several incisions were carried cautiously through the integuments and cellular substance until the surface of the turnor was distinctly perceived. The flaps were then dissected back on each side low enough to expose the whole of it, as far as its imbedding between the hamstrings would permit. Upon a careful exannination of the surface of the tumor now, it was discovered that muscular fibres, greatly extended and attenuated, fornied its surface; and by tracing the tumor, it was ascertained that the biceps-flexor-cruris was its exclusive seat. Some embarrassment and perplexity was here experienced as to the nature of the case. The idea that the muscle might be in a state of hypertrophy afforded the best, but not a satisfactory explanation. It was, however, determined to cut into the turnor in the direction of the fibres of the muscle, to ascertain, if possible, its nature. Accordingly the scalpel was introduced, by cautious dissection, and its entrance into a cavity was announced by the gush of blood and a thick fluid of a brownish complexion. The opening being enlarged sufficiently to admit the finger, its introduction discovered the existence of an extensive cavity. The semifluid which had continued to issue being now carefully pressed out, the opening was enlarged by extending the incisions quite to the extremities of the emptied cavity. After sponging out the wound, it was ascertained that a cyst, varying from one quarter to one half of an inch in thickness, bounded the cavity in which the matter had been confined. The next step in the operation was to dissect away the cyst, which was accom- 
plished with some difficulty on account of its great extent and deep imbedding between the hamstrings. Its removal was, at length, effected; and upon examining the cavity from which it lad been taken, it was satisfactorily ascertained that the cyst had been surrounded and covered in every part by the fibres of the biceps, and that the tumor must have originated within the belly and substance of the muscle. The cavity was cleared of blond; and as no arterial jets could be perceived, ligatures (of course) were not required, the bleeding being only of the oozing character. The flaps, which had been turned back, were now brought together and retained in apposition by stitches of the interrupterl suture, supported by adhesive straps, compresses and bandages.

The man suffered much during the operation, became faint, and required diffusible stimulants to restore the exhausted and sinking energies. Reaction came on after a short time, and the patient became comfortable, except the usual pain and smarting always succeeding surgical operations. Little traumatic fever followed, scarcely exceeding the elevated excitement of health. The pain of the muscle continued for some days. In six days the dressings were removed; at which lime, most of the wound had united by the first intention. In ten days from the time of the operation, the wound had healed, except a part of one of the faps, which from its extent, extreme thinness, and feeble circulation, became gangrenous and sloughed. At the date of this communication the man is well.

Remarks.-In the foregoing case there can be little reason to doubt that the tumor originated in rupture of some of the central fibres of the biceps-cruris, and that the accident must have occurred when the sensations of pain and giving way were first felt in the thigh. It is also very probable that effusion of blood took place at the same time into the cavity of the wound, which we may suppose was formed by retraction of the ruptured fibres of the muscle. The cyst which bounded the tumor, and constituted the parietes of its cavily, must have resulted from coagulable lymph, effused by the capillaries of the wounded and newly created surfaces during their adhesive efforts in a state of inflammation. Poured out from, and deposited upon these irritated and inflamed surfaces, the lymph became organized (as in ordinary cases, when it is the bond of union of divided parts), simply by elongation and extension into it, of the arterial and nervous capillaries of the supporting textures. But, in the present case, the surfaces not being allowed to approximate and reunite, in consequence of the contractions of the biceps, from the unrestrained motions of the limb, and the effused blood, the lymph became organized upon the surfaces of the wound, and formed into a membrane. Once formed, the actions of the cyst were maintained by an independent interstitial and irritative vitality, presiding over its economy, which, though feeble and imperfect, effected (nevertheless) its farther development and growth; and enabled it, likervise, to resist the absorbing powers of the surrounding textures. The internal surface of this newly-formed membrane possessed, also, absorbing and secreting propertics; and to the latter, the fluid (which filled the cavity and mainly influenced the enlargement of the tumor) must be attributed.

A cyst formed according to these views, may be regarded as a decidu- 
ous membrane, originating from infammation induced in unnatural or accidental surfaces, kept asunder, disturbed and irritated, during the efforts of the adhesive infarnmation. That such was the process in the formation of the cyst and tumor, of the preceding case, is at least probable.

The accident which originated the foregoing case is one of not very infrequent occurrence. I have nyself known several instances of it ; but a similar result has never before been witnessed by me. Having once been followed by troublesome, nay, dangerous consequences, the accident might again present a case similar or even of a more serious character. For this reason chiefly the case has been regarded as fraught with some interest, and communicated to the medical public with the following remediate suggestions.

After all such accidents it might be advisable to restrain the patient, as in cases of fracture ; to support the injured parts with compresses, rollers and splints ; and to maintain such confinement as the severity of the case may seem to demand. Should fever, or any other constitutional disturbances, occur, they should be promptly met by appropriate remedies. Every measure calculated to promote reunion should be adopted and rigidly enforced.

February 18, 1835.

\section{MEDICAL QUESTIONS.}

To the Editor of the Boston Medical and Surgical Journal.

Sir,-Reports not unfrequently reach us of certain individuals who have fallen victims to a prescribed course of regimen. These persons are said, by gentlemen who are entitled to the fullest confidence, to have pertinacicusly followed the course till they reached a point of reduction from which there was no recovery. If these are facts, they ought to be collected and published. And I beg leave, through your Journal, to request my medical brethren, if they have been called to advise in such cases, that they will have the kindness to answer, briefly, the following interrogatories, by mail, as early as convenient.

Should the substance of their replies ever be embodied in a small volume, they will not only receive a copy and the thanks of the author, but will have the pleasure to know they are assisting in the settlement of a question of great interest to the country. If it should appear probable that their patient was laboring under a decline at the conmencement of the change of diet, this ought in candor to be fully disclosed.

It will be perceived, by the tenor of the questions, that they are designed to embrace not only unfortunate results of a change of diet, but such as are favorable. There are, in our community, considerable numbers who have entirely excluded animal fond from their diet. It is exceedingly desirable that the results of such experiments, so difficult to be found in this land of plenty, should be ascertained and thrown before the profession and the community. Will physicians, then, have the kindness, if they know of any persons in their vicinity who bave excluded animal food from their diet for a year or over, to lend them this number 